ISSN: $1130-3743$

\title{
POR UNA ÉTICA DE LA COMPASIÓN EN LA EDUCACIÓN
}

\author{
Ethics of compassion in education
}

\section{Pour une éthique de la compassion dans l'éducation}

Maria Rosa BuXARraIs EsTRADA

Departamento de Teoría e Historia de la Educación. Universidad de Barcelona. Campus Mundet. Edifici de Llevant. Passeig de la Vall d'Hebrón, 171. 08035 Barcelona. Correo-e: mrbuxarrais@ub.edu

Fecha de recepción: enero de 2006

Fecha de aceptación definitiva: abril de 2006

BIBLID [(1130-3743) 18, 2006, 201-227]

RESUMEN

Uno de los principales retos actuales de la educación es incorporar la ética de compasión en sus premisas, tanto a nivel teórico como en la praxis educativa. En el presente artículo esbozamos los principales argumentos que nos invitan a introducir el sentimiento de la compasión en las propuestas pedagógicas de educación moral. Destacamos la complementariedad e intersección de planteamientos en el ámbito de la ética y el desarrollo moral que con diversas denominaciones vienen a considerar aspectos similares: ética de los sentimientos morales, ética del cuidado y la responsabilidad, ética de la alteridad, ética de la hospitalidad, entre otras. Por último, incidimos en dos aspectos que deberían tenerse en cuenta a la hora de realizar una pedagogía de la compasión en el ámbito moral: las relaciones entre profesor y alumno y el enfoque narrativo en el desarrollo moral.

Palabras clave: ética de la compasión, educación moral, sentimientos morales, ética del cuidado, alteridad. 


\section{SUMMARY}

One of the main challenges currently facing education is the incorporation of the ethics of compassion at the theoretical level as well as in educational practice. This article outlines the main arguments that permit us to introduce a sentiment of compassion in the pedagogical proposals for moral education. Emphasis is placed on the complementary nature of ethics and moral development which, under various denominations, consider similar aspects: ethics of moral sentiments; ethics of care and responsibility; ethics of otherness; and ethics of hospitality among others. Finally, we arrive at two features that should be considered when implementing the teaching of compassion in the moral realm: the relationship between students and teachers, and the narrative focus in moral development.

Key words: ethics of compassion, moral education, moral feelings, ethics of care, otherness.

\section{SOMMAIRE}

Un des principaux défis actuels de l'éducation est d'incorporer une éthique de la compassion dans ses prémisses, tant au niveau théorique que dans la praxis éducative. Dans le présent article nous ébauchons les principaux arguments qui nous invitent à introduire le sentiment de la compassion dans les propositions pédagogiques d'éducation morale. Nous soulignons la complémentarité et l'intersection de différentes approches dans le cadre de l'éthique et du développement moral qui, avec diverses dénominations, viennent considérer des aspects semblables: éthique des sentiments moraux, éthique des soins et de la responsabilité, éthique de l'altérité, éthique de l'hospitalité, entre autres. Finalement, nous énonçons deux aspects qui devraient être pris en considération au moment d'effectuer une pédagogie de la compassion dans le cadre moral: les relations entre professeur et élève et l'analyse narrative dans le développement moral.

Mots clef: éthique de la compassion, éducation morale, sentiments moraux, éthique des soins, altérité.

\section{INTRODUCCIÓN}

Vivimos en un momento histórico donde existe una tendencia exacerbada al individualismo, a interesarnos por nosotros mismos. Preocuparse por los demás, si no es acaso por los nuestros, constituye una rareza humana. Por lo que se hace indispensable potenciar la consideración de la gente hacia los demás. En este sentido, nos dice Camps $(1999,25)$ : "No se combate el individualismo negando el valor último de la individualidad, sino entendiendo que nadie puede ser auténtico individuo sin contar con el otro".

De todas formas, los que se han dedicado y dedican al estudio de la conducta moral pro-social en el contexto del Primer Mundo, de individualismo competitivo 
y escasa asistencia al otro, ven que todavía existen personas que se sacrifican por otras y que ayudan modestamente a los demás de forma constante, lo que aumenta la calidad de vida y hace posible la existencia social. No nos gustaría ser apocalípticos en extremo.

Nos vemos asediados cada día por imágenes desoladoras de un mundo que genera nuevas formas de "residuos humanos" (Bauman, 2005). Escuchamos discursos de predicadores del desánimo absoluto ante la globalización. Todo es posible, hay una ausencia de límites entre lo que está bien y lo que está mal, por lo que cualquier decisión que tomemos puede ser reversible, provisional o gratuita. Así, los compromisos dejan de ser sólidos y duraderos, siguiendo a Bauman (2005) son la expresión de un amor líquido. La persona que se preocupa por las demás sale a la superficie, porque se compromete con el otro sin reservas, y llega a convertirse en héroe.

Por otra parte, los expertos, los informes y los análisis nos alertan del peligro y amenaza de una población en aumento de personas inactivas que para vivir dependen de las activas, de las que aportan con su trabajo un valor a la sociedad. Se interioriza la imagen de una sociedad dividida entre activos y dependientes. Crece la vulnerabilidad de masas y el sentimiento de inseguridad social (Castel, 1991) cuyo efecto es la fragmentación y la desintegración del conflicto social en la confrontación entre grupos e intereses diversos. Se multiplican los individuos "dependientes", mujeres, personas mayores que ejercen funciones sociales no reconocidas, como cuidar a niños, enfermos, abuelos, vecinos, la casa, etc., funciones sin las que la independencia de los demás no sería posible. Aquí valores como la compasión no deben menospreciarse.

En los últimos años, hemos asistido a la proliferación de trabajos relativos a la compasión ${ }^{1}$, pero cualquier propuesta actual que se elabore sobre ética de la compasión en el ámbito de la Pedagogía debe referenciar los trabajos de Joan Carles Mèlich de la Universidad Autónoma de Barcelona, Fernando Bárcena de la Universidad Complutense y los de Pedro Ortega y Ramón Mínguez de la Universidad de Murcia, quienes se lanzaron, cuando todavía no estaba en boga, a hablar del tema. Sus ideas, entre otras, han servido de inspiración y de referente en la elaboración del presente artículo. Para conseguir nuestro cometido también hemos creído necesario acudir al contexto ético-filosófico para beber de sus fuentes realizando un acercamiento a dicho contexto.

Parece que tratar la ética de la compasión supone toparse con intersecciones. Aparecen coincidencias con la ética de los sentimientos morales, la ética de la alteridad, la ética de la hospitalidad y de la acogida, la ética del cuidado y la responsabilidad, todo un ir y venir de éticas que, en estos momentos, ocupan la mayor

1. A pesar de que quien ha puesto de moda la palabra "compasión" ha sido el actual presidente de los Estados Unidos, George Bush jr., no tenemos ninguna intención de recurrir a la idea de compasión que éste propone. 
parte del terreno de la educación moral. Uno de nuestros principales objetivos es ofrecer algunas pinceladas de estas éticas estableciendo sus posibles conexiones con el ámbito pedagógico.

Desde hace casi dos décadas venimos trabajando en el modelo de construcción de la personalidad moral cuyo último objetivo se ha centrado en el desarrollo de la sensibilidad valorativo-moral —sentimientos morales—, el juicio valorativo-moral — juicios morales-y la autorregulación o componente volitivo - conducta moral-, que comprende la toma de decisiones y la acción consecuente con los sentimientos y juicios morales. Quizás los procedimientos que han sido utilizados en la educación en valores no han enfatizado la cuestión de la sensibilidad moral, tal y como en estos momentos reclama la sociedad. El gran problema con el que nos enfrentamos día a día es que los chicos y las chicas son capaces de argumentar lo que está bien o lo que está mal, pero han perdido sensibilidad moral y están poco entrenados en cambiar su comportamiento adecuándolo a lo que consideran valioso. Pretendemos una educación moral que atienda simultáneamente la vía afectiva, cognitiva y volitiva de la persona.

Siempre hemos tenido presente que cualquier aportación teórica que nos ayude a llenar los vacíos de los que adolece nuestro modelo, bienvenida sea. Así, y una vez realizada una revisión bibliográfica sobre el tema de la ética de la compasión, estamos de acuerdo con Ortega (1997) cuando defiende la urgencia de rescatar esta ética, de la solidaridad y del compromiso con el "otro".

Como comentaba Berkowitz en un artículo publicado en español en la Revista Iberomericana de Educación en el 1996, citado por Ortega, "nos obstinamos en explicar y controlar la conducta humana con modelos simplistas muy restringidos, en lugar de abarcar la complejidad y la riqueza de la dinámica humana y buscar soluciones igualmente complejas y ricas". Nuestro afán por cumplir con este objetivo ha hecho que siempre miráramos a diversos autores de diversas disciplinas que nos servían de referentes para completar nuestro modelo de educación moral. Hemos recurrido a la psicología (Piaget, Kohlberg, Bandura, Hoffman, Gilligan, Berkowitz, Selman, Nucci, etc.), a la filosofía (Cortina, Habermas, Rawls, MacIntire, Guisan, Jonas), a la sociología (Durkheim) y a la pedagogía².

La mutación que están sufriendo las sociedades, que se adjetivan de plurales, abiertas y heterogéneas, caracterizadas por la diversidad y la multiculturalidad generada por las migraciones en aumento, las diferencias norte-sur, los problemas de violencia, y otros, nos obligan a realizar una apuesta por un modelo de educación moral que contemple la compasión.

2. He aquí una muestra significativa de autores. No consideramos citar aquí todos los autores que son referentes en nuestra manera de entender la educación moral, porque ya han sido referenciados en otros trabajos. 


\section{LA COMPASIÓN ES UN SENTIMIENTO}

Adquirimos conocimiento del mundo mediante sensaciones. Sentir supone un modo elemental de ser consciente de lo que nos rodea — realidad externa-y de nuestro interior. De la concordancia entre la realidad externa y la propia se es consciente mediante la reacción que provoca esa concomitancia; a esa respuesta subjetiva de lo objetivo en el plano de los apetitos, de lo que deseamos o no, de lo que nos atrae o repele se denomina afectividad (Bernal, 2002, 83).

La compasión es un sentimiento que se estructura, básicamente como todo afecto, a base de placer y de dolor. Como cualquier otro sentimiento, nos hace ser conscientes, proporcionando un nivel elemental de la actividad del saber, una valoración de la realidad de alguien, mostrando al mismo tiempo el grado de vinculación que tenemos con los demás. La apreciación sentimental de la realidad sirve para actuar de una forma y otra. Los afectos excitan movimientos en la intimidad: deseos.

Normalmente cuando oímos la palabra compasión la relacionamos con el sentimiento de lástima por alguien. Según el Diccionario de la Lengua Española, compasión significa "sentimiento de conmiseración y lástima que se tiene hacia quienes sufren penalidades y desgracias". Sin duda, se trata de una concepción incompleta o equivocada, porque en realidad la compasión implica un sentimiento genuino de preocupación por el bienestar de los demás.

Si nos fijamos en el origen de la palabra compasión: cum, "junto"; passio, "sentir", o sea, "Sentir juntos"; o bien, "ponerse en el lugar del otro", está muy lejos de significar la pobreza de la simple lástima o del dolor más de pose que auténtico. Se trata del reto de hacerse uno con el otro, de traspasar el estrecho horizonte del individualismo y reconocer que todo otro es otro-como-yo, no una abstracción. Este sentimiento originario, sentirse mal por el dolor que sufre otro, expresa una capacidad humana de comprender el estado emocional de otras personas a la que se denomina empatía, o simpatía.

En general, las personas tenemos facilidad, aunque no todas por igual ${ }^{3}$, de sentir cómo y cuándo otros sienten. Se dan un conjunto de sentimientos, muestras espontáneas de la sociabilidad de nuestro modo de ser. La forma de evaluar el grado de dolor que tienen las personas hacia las que mostramos compasión depende del estilo temperamental de cada persona, en el que la educación, las costumbres, en

3. La "doctrina del pecado original" asume que las personas nacen egoístas y adquieren conciencia moral mediante una socialización que controle el egoísmo, encuentra un cierto paralelismo en la primera época del freudismo y en la teoría del aprendizaje social, que subrayan la importancia para el desarrollo moral de que los padres premien y castiguen, sobre todo dando o negando el cariño. Diametralmente opuesta está "la doctrina de la pureza innata" vinculada a Rousseau, quien creía que los niños son buenos por naturaleza — sensibles hacia los demás- pero vulnerables a la corrupción de la sociedad; tiene un paralelo aproximado en la teoría de Piaget en el sentido de que su relación con los adultos acusa el respeto heteronómico a las normas y a la autoridad que afecta su desarrollo moral. 
definitiva, la cultura adquirida y el cultivo de sí mismo — el carácter - constituyen la fuente de referencia. Las personas sienten la carencia de lo debido a otros y de lo merecido: sienten compasión. Pero la intensidad del afecto oscila según qué se valore de los seres humanos, qué se considere que es malo en ellos o para ellos, y qué vínculos haya con los otros (Bernal, 2002).

La compasión se relaciona con otros sentimientos: lástima, conmiseración, ternura y piedad. Si se equipara la compasión a un tipo de hábito, no con el significado habitual del sentirse, sino con la cualidad que conduce a la ejecución de un tipo de acciones, precedidas o acompañadas de un afecto de dolor por la pena ajena, entonces encontramos que se presenta como sinónimo de misericordia, piedad, clemencia, solidaridad y beneficencia. La mayoría de personas que demuestran el sentido de la compasión cuando se les pregunta por qué lo hacen - dedicar su tiempo como voluntarios, por ejemplo_ alude a razones pragmáticas: "me saca de casa" $\mathrm{O}$ "me da algo que hacer", u otras explicaciones aceptables para evitar ser etiquetado "hermanita de la caridad" o "defensora de causas perdidas". Eso no debería ser así. Cuando reconozcamos que la compasión es una práctica intrínseca de nuestra naturaleza humana y que el egoísmo desenfrenado no gobierna de forma inevitable nuestra conducta, empezaremos a valorar los beneficios de la atención y la compasión en la sociedad.

Volviendo a que la compasión es un sentimiento que consiste en sentir dolor al conocer que otros sufren, añadámosle el sentimiento de ternura y lástima que se tiene del trabajo, desgracia o mal que padece alguien. La diferencia entre la compasión y la lástima es, por un lado, para acentuar el grado de vehemencia en el sentir y sentirse, mayor en la compasión que en la lástima, y, por otro, se ha reservado utilizar la noción de lástima para nombrar ese dolerse ante el daño de los animales.

La ternura, sin embargo, es un afecto en la mayoría de los casos correlativo al sentir dolor, y que consiste en valorar a la persona que manifiesta ese dolor, a pesar de su dolor o debilidad, mostrándose amable o cariñoso, sugiriendo que, a pesar de su mal y de su vulnerabilidad, atrae, es digno de empujar al amor, al gusto por las personas en ese plano sensible (Lewis, 1994, 49). La ternura es un acto muy unido a actos que se dirigen al que sufre, para ayudarle, aliviarle, consolarle, etc. Este tipo de afecto supone una atracción por lo que está desvalido, que puede mover a actuar protegiéndole y cuidándole. Se ha considerado la ternura como un sentimiento profundamente femenino, al unirlo a la maternidad, las mujeres parecen mostrar mejor la ternura porque tienden a ser más sensibles ante la debilidad humana.

Nos resulta difícil entender nuestros sentimientos porque consisten en sentirse y no en conocerse. Son tan subjetivos que sabemos que, al hacerlos objetivos para conocerlos, nos perdemos algo de su realidad. De todas formas, mediante la compasión exploramos qué tendencias poseemos respecto a los demás, es decir, cómo es nuestra sociabilidad, dentro de lo que cabe destacar nuestra inclinación o no a unirnos con los demás, que en eso versa la solidaridad. 
En la historia del pensamiento se reconocen dos grandes modos de elucidar acerca de la compasión: uno de ellos consiste en sostener que sentimos lo que sentimos al compadecernos por amor de los demás, entendiendo por amor el deseo del bien del otro porque nos corresponde, o por sí mismo, o por las dos razones al mismo tiempo, de otra forma se aclara que la compasión obedece al temor a padecer ese mal que sufren otros, es decir, se repele lo que pasa al otro porque se rechaza que le sobrevenga a uno. En este sentido, "sentir compasión no es tener un corazón que se desangra por los otros: la compasión es un amor tan profundo, que es capaz de hacer cualquier cosa necesaria para llevar conciencia hacia una situación" (Sanz de Santamaría, 2005). E incluso puede acaecer que una persona se compadezca por amor o por temor, o por ambos afectos a la vez, mueve a pensar cómo son las personas que reaccionan así (Bernal, 2002, 90).

Sin entrar en detalle por todas las propuestas ético-filosóficas que se han realizado sobre este tema, consideramos necesario citar a Aurelio Arteta quien escribió un libro titulado La compasión, donde se recogen muchos de los aspectos aquí mencionados. En la lectura de su obra hemos detectado que no hay unanimidad a la hora de valorar la compasión.

Arteta $(1996,57)$ nos proporciona elementos o características que definen la compasión: 1) se funda en la dignidad y finitud del hombre, 2) es nominalista o toma cuerpo en las personas, 3) es universal, 4) es una virtud y no sólo una emoción o pura espontaneidad fuera del control de la razón. Ha de desembocar en la lucha por la justicia, 5) se ejerce preferentemente con los más débiles, en aquellos que la sociedad ha condenado a la miseria y la marginación. Por otra parte, Mate $(1992,292)$ afirma que "este sentimiento hacia el otro como hacia un sujeto ultrajado pero con exigencias de dignidad es la com-pasión".

Aristóteles en la Retórica nos dice que «Sea la compasión cierta pena por un mal que aparece grave y penoso en quien no lo merece, el cual mal se podría esperar padecerlo uno mismo o alguno de los allegados, y esto cuando aparezca cercano".

Rousseau fue el primero en otorgar un sentido naturalista a la compasión. En su Emilio, el filósofo alude a un "sentimiento natural que, moderando en cada individuo la actividad del amor a sí mismo, concurre a la conservación mutua de toda la especie". Y lo explica así: "Nos inspira una repugnancia natural ver perecer o sufrir a cualquier ser sensible, y principalmente a nuestros semejantes", lo cual nos lleva "en socorro de aquellos a quienes vemos sufrir".

Kant, que también cuestionaba ese utópico estado de naturaleza rousseauniano, realiza dos importantes críticas a la compasión: dice que es débil (a) y que es siempre ciega (b). (a) "No es posible que nuestro pecho se interese delicadamente por todo hombre ni que toda pena extraña despierte nuestra compasión. De otro modo, el virtuoso estaría, como Heráclito, continuamente deshecho en lágrimas, y con toda su bondad no vendría a ser más que un holgazán tierno". (b) "Es ciega porque puede hacer conmovernos ante alguien cercano o simpático y dejarnos indiferentes, en cambio, ante desgracias mayores pero alejadas". 
Fue Freud quien más sistemática y formalmente denunció la vana ilusión de contemplar al hombre como un ser amable por naturaleza.

Pero sin duda, uno de los mayores defensores de la compasión fue Schopenhauer. Su hilo argumental comienza quebrando el principio de individuación, algo que abre la puerta de la simpatía y el amor hacia los demás, y que concluye, pese a todo, con una visión negativa de la felicidad. De hecho, para él, el optimismo es "no sólo absurdo, sino verdaderamente impío, pues es un sarcasmo contra los dolores sin cuento de la humanidad". Es, por tanto, en este marco que he perfilado desde donde cabe contemplar la buena prensa que para este filósofo tenía la compasión.

Por otra parte, no podemos dejar de considerar la postura de Nietzche, en cuanto a la crítica que le hace a Schopenhauer, lamentándose de que éste racionalice la moral cristiana, hecho que considera fraudulento. Nietzche sostiene que la compasión es una virtud tramposa, que necesita de la miseria ajena para sobrellevar la propia. Tilda al compasivo de "mono orgulloso, que está incesantemente descontento consigo mismo". Es un ser que padece y que, por vanidad, necesita com-padecer. Y es "el socorro de ese dolor ajeno lo que propicia al compasivo el sentimiento de superioridad respecto al otro".

Se hace imprescindible un auténtico giro antropológico, es decir, una vuelta al ser humano, de parte de todas las disciplinas y la pedagogía no puede ser la excepción. Elemento vital para este llamado "giro antropológico", será la búsqueda urgente de lo que llamaba en el inicio de las reflexiones, una verdadera ética de la compasión.

La compasión aparece como el contexto radical que renuncia a la presentación estratégica ante el otro (Boff, 1999), asumiendo que toda persona, de cualquier condición, ha de tener la oportunidad de dar de sí.

Este planteamiento ético asume la tradición oriental que enmarca la construcción de la ética dentro de una perspectiva de la compasión infinita y la implicación del sistema emocional, en tanto que heurística hacia la deliberación moral, como en el caso del budismo (Dalai Lama, 2000). Se instituye en perspectiva moral, dentro de un debate abierto entre perspectivas de género diferenciadas.

La compasión puede movilizarnos a la acción sólo si se da una conexión con la razón o la voluntad, que sólo se produce entre iguales y que se traduce en sentimiento colectivo. Desde la perspectiva de Ortega y Mínguez (2001) la compasión se convierte en ayuda, compromiso o denuncia, fundamentando el reconocimiento de mi responsabilidad frente al otro, cualquier otro. La enlazan con la educación moral, porque ésta se orienta, desde la inevitable reflexión moral, hacia la praxis de la compasión y la solidaridad del reconocimiento del otro en su dignidad ultrajada, de la empatía y simpatía, de la denuncia y del encuentro con el hombre.

Probablemente, no sé si todos, pero una enorme cantidad de los problemas a los que se enfrenta la praxis de la pedagogía se verían resueltos, con un poco de esta solidaridad afectiva a la que llamamos compasión. Los tiempos que corren, agitados, "efectivistas", llenos de resultados necesariamente exitosos, de pretender que con la razón y con nuestras habilidades lo podemos todo, pueden hacernos creer 
que el consuelo, la compasión, las lágrimas, son un tiempo perdido, incluso hay quienes dicen que manifestar compasión es signo de debilidad.

Pero redescubrir la compasión, será redescubrir al otro que llora-como yo, al que le duele-como a mí, que se alegra-como yo, que se ve poseído por el miedo-como yo.

\section{3. ÉTICA DE LOS SENTIMIENTOS MORALES}

Precisamente por ser la compasión un sentimiento, nos conduce directamente a tratar la ética de los sentimientos morales. Constituye hoy una convicción psicológica ampliamente aceptada que los sentimientos y emociones morales son fundamentales para el desarrollo de la sensibilidad moral o la capacidad del sujeto para percibir y reconocer los conflictos y problemas morales que la vida social nos ofrece. Es a partir de lo que sentimos que realizamos el proceso de clarificación de valores, porque las situaciones vividas están cargadas de sentimientos que se transforman en valores a través de un proceso cognitivo-racional. Los sentimientos morales van a marcar la dirección de nuestra conducta.

Ya Hume en su Tratado de la Naturaleza Humana en 1739 reconocía toda la fuerza moral en los sentimientos y defendía un mínimo natural en ética arraigado en la sensibilidad humana. Destacaba que la moralidad habita en el interior del ser humano. Esta ética se basa en un concepto ampliado de racionalidad que atiende no sólo al pensar y razonar, sino también a la capacidad de sentir y sufrir. Apelamos a una ética atenta a las emociones y a los sentimientos morales, y no sólo a la razón.

Porque los sentimientos nos ayudan en la construcción de nuestra propia biografía, a establecer una vinculación afectiva eficaz y a la vez nos permiten mantener una organización jerarquizada y flexible de nuestra matriz de valores (Tey, 2005). Al experimentar un sentimiento nuestra atención es captada por el mismo y se convierte en importante, susceptible de análisis y valoración porque nos afecta a nosotros y al entorno.

Por otra parte, si consideramos que los sentimientos tienen su origen en las relaciones seguramente también podemos considerar el papel de los mecanismos interpersonales en todo el proceso. Nos apoyamos en Strawson $(1995,42)$ cuando insiste en "la importancia que damos a nuestras actitudes e intenciones que adoptan en relación con nosotros, otros seres humanos y, en gran medida, en que nuestros sentimientos y reacciones personales dependen de, o involucran, nuestras creencias alrededor de estas actitudes e intenciones". Este autor nos ofrece una propuesta acerca de la función de los sentimientos morales con respecto a la moral, que será considerada por Hoyos $(2004,56)$ cuando advierte que son sobre todo los jóvenes quienes han verificado lo fundamental que es valorar la sensibilidad moral, así ésta signifique al mismo tiempo cierta crítica al rigorismo moral y al moralismo de otras épocas. La conciencia moral contemporánea ha sido perjudicada en demasía por su olvido de la sensibilidad, el pensar que hablar de sentimientos y valores 
morales es anacrónico. En los últimos años, parece que esto no es del todo cierto. Se está dando un impulso a la cuestión de los sentimientos y emociones morales que, incluso, en ocasiones, puede resultar pesado ${ }^{4}$.

Hay una vuelta a los sentimientos morales, ¿acaso son algunos grupos sociales quienes las han potenciado? -nos referimos a las mujeres y la juventud-. Para empezar se han propuesto definiciones sobre los mismos. Tey y Martínez (2003) los definen como aquel tipo de sentimientos que ayudan a promover la excelencia, tan individual como la referida a la vida comunitaria; son sentimientos generados en las relaciones, en la convivencia y, pese a que se viven de forma personal e intransferible, su naturaleza no es meramente subjetiva, sino que además presentan una dimensión inter-subjetiva. Se trata de indicadores de moralidad y una especie de mediadores entre el mundo de las experiencias, donde se muestran los hechos morales y el mundo de las leyes, que integran los principios morales. Son también factores de nuestra conciencia que nos recuerdan que somos objeto de derechos pero también de deberes ya que nos hacen conscientes de las reglas prácticas que deben posibilitar o no lo que debe impregnar la vida en comunidad.

Hoyos (2004) por su parte, aboga por tres sentimientos de especial significación con respecto a la conciencia moral: el resentimiento, la indignación y la culpa. El resentimiento es mi sentimiento al ser ofendido por otro, cuando considero que él efectivamente estaba en sus cabales. Si esto no es así, debo suspender mi actitud resentida, ya que él en esa acción no podría controlarse, en cierta manera no era dueño de sí, no era él. Otro sentimiento es el de indignación, cuando nos damos cuenta de que un tercero injuria a otro como si lo hubiera hecho con usted o conmigo. En este escenario somos espectadores, pero no de algo objetivo sino inter-subjetivo, nos descubre una especie de implícito de solidaridad humana. Y la culpa, por la cual nos avergonzamos de la ofensa y del mal que hemos provocado en otro. Ahora somos nosotros los agentes, no los pacientes ni observadores, de acciones que lesionan los derechos de los otros.

Hay situaciones humanas tan complejas que parecen reunir las condiciones inhumanas indicadas aquí en una sola: la guerra, el secuestro, la violación son negaciones de todo reconocimiento. Parecen haber tomado un nuevo impulso los sentimientos y sus contrapartidas positivas - sentimientos morales-, el agradecimiento, el perdón, la compasión, el reconocimiento, la solidaridad. Éstos constituyen una especie de sistema de relaciones interpersonales que dan cohesión a las organizaciones y al tejido social.

Desde otro punto de vista, Tugendhat (1999) define los sentimientos morales como sensores o alarmas que se activan en situaciones de interacción social que

4. Son muchas las ofertas que se realizan no sólo en las instituciones escolares sino en la vida cotidiana de cursos sobre la gestión de los sentimientos morales, la inteligencia emocional propuesta por el trabajo de GOLEMAN (1996), la alfabetización emocional, libertad emocional, etc. Todas con el objetivo de conseguir un bienestar emocional de dificil consecución en una sociedad como la nuestra. 
nos exigen justificar acciones asumidas voluntariamente en una comunidad, por lo que la sensibilidad y los sentimientos morales son inherentes a la persona por el simple hecho de serlo, somos seres que pensamos y sentimos.

En el mundo de los afectos y los sentimientos morales construimos la conciencia moral. Las personas tenemos conciencia porque somos capaces de relacionarnos emocionalmente con las demás, porque sentimos compasión, piedad, amor hacia los que nos rodean, porque tenemos la íntima sensación de que no podemos maltratar a los otros - aunque sean desconocidos - porque se nos exige actuar de acuerdo con unos criterios morales que nos dicen lo que podemos hacer y lo que no, por lo tanto, la conciencia no existe sin un vínculo emocional hacia alguien o algo, y de este modo la conciencia está íntimamente unida con el conjunto de emociones que llamamos "amor" (Scout, 2005). Cada vez nos encontramos con mayor número de individuos que, por desgracia, son incapaces de darse cuenta de que los demás tienen sentimientos y son incapaces de captar los estados de ánimo derivados de sus actuaciones ${ }^{5}$.

La conciencia moral no nos invita al despotismo de la libertad sino al reconocimiento de su fragilidad porque no siempre nuestra conciencia actúa rectamente. No sólo nos da noticia o informa de la acción que hemos realizado sino que nos evalúa la acción dándonos noticia de su bondad o maldad, licitud o ilicitud. Nos dice Tugedhat que la conciencia moral es un instinto: el de juzgarse a sí mismo conforme a la moral. ¿Pero conforme a qué tipo de moral nos juzgamos? En eso radica nuestra principal preocupación como educadores, no dejarnos vencer por el relativismo moral imperante en nuestra sociedad.

El ser humano cuando actúa moralmente, con conciencia moral, no es sólo un agente moral al que se le pueden imputar unas acciones, ni sólo un actor moral que responde con una acción ante una situación, sino un autor moral, porque tiene la posibilidad de hacer inteligible sus acciones desde sí mismo. Así pues, la conciencia es una capacidad que la adquirimos en la medida que nos hacemos cargo de nuestros actos y rendimos cuentas de los mismos, nos hacemos responsables de ellos. En ella se integran el momento de juicio y el momento de aplicación. Se trata de un instinto, no de una mera facultad de enjuiciamiento.

5. Vicente GARRIDO (2005) constata que están aumentando los casos de jóvenes que no desarrollan la conciencia. Declara que la conciencia es nuestra guía moral, lo que nos pone unas obligaciones hacia los otros, la que nos exige ser responsables de nuestros actos y esto es posible porque hemos desarrollado la capacidad de preocuparnos por el bienestar de los otros, porque somos capaces de querer y aceptar el amor de ellos. El razonamiento moral es el proceso del pensamiento que asiste a la conciencia. 


\section{LA ÉTICA DEL CUIDADO Y LA RESPONSABILIDAD}

Siguiendo con los efectos de la conciencia moral vamos a incursionar en el terreno de la preocupación por el otro, del cuidado, de la afectividad, etc. Las teorías actuales sobre el desarrollo moral pro-social tienden a centrarse en una sola dimensión, y cada una tiene sus propios métodos explicativos. Por ejemplo, las teorías del aprendizaje social se fijan en el comportamiento de ayuda y se han especializado en los procesos implicados en el premio y el castigo y la imitación. Los teóricos cognitivistas y del desarrollo se centran en el razonamiento moral y usan conceptos como toma de perspectiva, reciprocidad, desequilibrio cognitivo, construcción progresiva y co-construcción (Buxarrais, 2000). Y las teorías del desarrollo emocional y motivacional, especialmente sobre el desarrollo de la empatía, el sentimiento de culpa y la interiorización moral. Situamos la aportación de Gilligan en las últimas.

Desde la perspectiva de Carol Gilligan en el desarrollo moral, expuesta en In a Different Voice (1982) se destacan diferencias en el conocimiento moral de las mujeres y los hombres. Argumenta, sobre la base de estudios realizados, que los hombres y las mujeres normalmente interpretan los problemas morales desde dos planteamientos distintos, implicando concepciones distintas del yo y de la relación del yo con los otros. Este planteamiento ha sido denominado como ética del cuidado y la responsabilidad ${ }^{6}$. Este tipo de ética aduce que las mujeres realizamos una interpretación más contextual de la moralidad, enraizada en las responsabilidades concretas de los individuos particulares, y en un autoentendimiento del yo basado sobre la interdependencia, el afecto o la relación y el cuidado hacia los otros.

La ética del cuidado, como perspectiva para la elaboración de un contexto de educación moral, se fundamenta en el evidente hecho de que toda educación se promueve desde una actitud y aptitud para el cuidado. La educación transcurre como un proceso de humanización, al tiempo que instituye un proceso de acción bumanitaria.

El cuidado alcanza su forma más espectacular cuando una persona arriesga deliberadamente su salud y seguridad por el bienestar de los otros. El cuidado está motivado por la compasión 7 .

6. El concepto de "care" nos sitúa en la órbita de la entrega, la disponibilidad, la compasión, la donación gratuita. Permite enlazar lo público con lo privado, lo que es próximo con lo alejado, los lugares de sociabilidad como la familia y las instituciones. En BrugĖre, F. (2006) La sollicitude. La nouvelle donnée afective des perspectives feministes y ZaCCAï-REYNERS, N. (2006) Respect, réciprocité et relations assimétriques. Quelques figures de la relation de soin, Esprit, Paris, enero. www.esprit.presse.fr, 20 de diciembre de 2005.

7. TAYLOR $(2002,182)$ dice que la ayuda que prestamos a los demás como otras formas de cuidado es impulsada por varias sustancias químicas neuronales diferentes, por las normas y papeles culturales y, sólo a veces, por las emociones a las que achacamos su origen. Algunas son específicas de cada sexo. Considerada toda la atención, cerca del $79 \%$ las proporcionan las madres, hijas y esposas. Las hijas 
Explica la acción humana en cinco tipos de encuentros o dilemas morales. El primero, el más sencillo, presenta al individuo como espectador inocente del dolor o de los problemas de otro - físicos, emocionales o económicos- La cuestión moral subyacente es si le ayudará o cómo se sentirá si no lo hace. En el segundo tipo, el individuo es un trasgresor que está haciendo daño a alguien o a punto de hacerlo y la cuestión moral es si se abstendrá de dañarle o al menos se sentirá culpable. En el tercero, combina elementos de los dos primeros, el hombre o la mujer es un trasgresor virtual que, aun siendo inocente, cree que ha hecho daño a alguien. El cuarto tipo de encuentro es más complejo: implica a varios interpelantes morales entre los que está obligado a elegir y la cuestión moral es: ¿a quién ayudamos?, ¿me siento culpable de haber preferido a uno entre varios? Y el quinto, cuidado o justicia, aunque también incluye varios interpelantes morales introduce una colisión entre el interés por los demás y cuestiones más abstractas como los derechos, el deber y la reciprocidad y la cuestión moral es en este caso si prevalece el principio de cuidado o el de justicia, y si uno se siente culpable de faltar al otro.

La principal pretensión de Gilligan consiste en eliminar tensiones, entre la inteligencia y la emoción, resaltando la relevancia de virtudes cálidas, como la benevolencia y la empatía, para llenar de contenido principios éticos importantes carentes de sustancia, como sería el caso del principio de imparcialidad, que "no puede aplicarse sin otro principio que determine los criterios pertinentes". Esta autora se rebela contra las éticas excesivamente formales, proponiendo, frente a la ética de los derechos, la ética de la responsabilidad en la que tengan cabida juicios en base "a sentimientos de empatía y compasión", de modo que, a través de una maduración personal, se resuelvan los conflictos entre la compasión y la autonomía (o, lo que es igual, los conflictos entre el cuidado ajeno y el cuidado propio).

Dentro de esta concepción "femenina" del desarrollo moral, el nivel postconvencional kohlbergiano cambia de contenido y sentido. Ahora ya no existe un orden rígido de prioridades axiológicas, dentro del cual el derecho a la vida prima sobre el derecho de propiedad, por poner un ejemplo. La ética "femenina" es teleológica y consecuencialista, de tal suerte que "el derecho a la propiedad y el derecho a la vida son sopesados no en abstracto, en función de una prioridad lógica, sino en lo particular, en las consecuencias reales que la violación de tales derechos tendrá sobre la vida de las personas en cuestión".

De igual modo, dentro de este reformulado y "feminizado" nivel postconvencional, "la responsabilidad del cuidado incluye a la vez al yo y a los otros, y el mandato de no causar daño, liberado de frenos convencionales, sostiene el ideal de cuidados y atención...".

Además de otras muchas ventajas frente a las omnipresentes éticas "masculinas", la ética "femenina" del cuidado, la responsabilidad y los sentimientos morales

cuidan de sus padres ancianos, las madres atienden a los hijos imposibilitados y, en general, las mujeres se dedican a sus esposos. 
presenta el valor añadido de su vocación de fuerza compensadora y complementaria, rehuyendo un protagonismo exclusivista o excluyente que pudiese mutilar al ser humano en su integridad, al tiempo que propiciando el diálogo entre la imparcialidad ("masculina") y el cuidado ("femenino"), para ayudar a una mejor relación entre los sexos y una maduración de la sociedad.

Lo que estos debates, en su conjunto, intentan poner de relieve es la existencia de una ética y de una racionalidad política divergente al patrón masculino universalista. No es simplemente una apelación a la diferencia, es más bien una reafirmación de un pensar feminista centrado en la especificidad del cuerpo femenino, y en la valoración social de la maternidad ${ }^{8}$. Se trata, en otras palabras, de establecer una ética de la responsabilidad y volver al cuidado, un tema políticamente relevante.

En resumen, en esta perspectiva adquieren un relieve más importante el papel de las motivaciones para actuar, las consecuencias de las decisiones en el largo plazo y la atención reflexiva sobre las emociones involucradas en las situaciones donde los sujetos quedan comprometidos y en las afiliaciones sociales en las que los sujetos participan. Por estos motivos, se suman al debate los resultados de las investigaciones, como las de Constance Holstein (1969), que comprueban la existencia de parcialidades de género en la calificación de dilemas morales. Estas investigaciones son ampliadas por Carol Gilligan (1982) y Nel Noddings (2002). Reúne un desasosiego experiencial por el que la práctica de la educación moral comprueba que no es suficiente para el desarrollo del compromiso moral la concepción imparcialista de la justicia (Blum, 1994). Recupera la atención emocional y deliberativa sobre los temas que el sentido de la corporeidad plantea (Grün, 2001), identifica la transversalidad interdisciplinar, en la que la preocupación formativa alcanza a todos los profesores implicados en el currículo, como la presentación de la ciencia con conciencia (Morin, 1982). Son planteamientos que se contienen en el proyecto de una "ética mundial", cuyos planteamientos puedan ser compartidos, en tanto que heurísticas que superen los condicionamientos que llevaron al choque de civilizaciones (Kung, 1992).

La compasión, promovida por este tipo de éticas, es moral. Nos descubre el poder de la relación con el más débil, las minorías, las personas dependientes. Reivindica la voz olvidada de muchas mujeres para quienes el verdadero problema moral empieza por la valoración del vínculo de la compasión, el valor de dejarse compadecer. Asegurar las funciones vitales de un ser vulnerable - del recién

8. Los costes de la atención y el cuidado pueden ser grandes. Resulta estresante, demoledor y crónico. Más de la mitad de las personas que cuidan de los demás trabajan fuera del hogar y muchas precisan abandonar sus empleos o reducir sus jornadas laborales para amoldarse al tiempo que requiere el cuidado, como media más de diez horas diarias. Interfiere con las restantes actividades necesarias de la vida, entre las que se incluyen el trabajo, la crianza de los hijos, llevar el hogar u ocuparse de las propias necesidades personales. Como resultado, las cuidadoras corren el riesgo de padecer problemas físicos y mentales. 
nacido para la madre, del abuelo que no puede valerse por sí mismo- no puede ser impersonal o neutro afectivamente. Las mujeres nos encontramos inmersas en relaciones de ayuda que siempre son asimétricas. La ética del cuidado se olvida de las perspectivas de las relaciones simétricas y de justicia desde la equidad. Va más allá del respeto, la tolerancia, la igualdad, el derecho y constata que el conflicto se expresa en términos de responsabilidad. Sin negarla, suma a la justicia el valor del cuidado. Reivindica el valor de las profesiones cada día más menospreciadas como las educativas, la relación de ayuda, de compasión y cuidado, en general, reservadas a las mujeres.

Pero si contemplamos las diversas formas de cuidado que existen en la sociedad, todas están marcadas por la experiencia de la creación de lazos afectivos (Taylor, 2002, 195). El hecho de que los lazos sociales consigan rechazar potentes virus gripales o retardar el avance de las enfermedades crónicas expresa su poder.

Además, esta corriente implica una apertura hacia la consideración de la importancia que, sin duda alguna, tienen las relaciones interpersonales en la construcción de la moralidad. Por lo que tratar la ética del cuidado nos lleva a referirnos al papel de la empatía en el desarrollo moral. Para Benhabid (1992) la empatía supone el interés del hombre por los demás, hace posible la vida social. Nos ponemos en el lugar del otro: el lugar que ocupa la vulnerabilidad, la fragilidad y la debilidad que las personas aportan. La persona es un espectador inocente cuando ve que alguien sufre, está en peligro o padece cualquier otra forma de aflicción. La cuestión moral que plantean estos estados es si el espectador está motivado para ayudar y, en caso afirmativo, en qué medida la motivación es interesada o se basa por el contrario en una preocupación real por la víctima.

Los psicólogos definen la empatía de dos modos: 1) como la conciencia cognitiva de los estados internos de otra persona, es decir, de sus pensamientos, percepciones, sentimientos e intenciones (Ickes, 1997) o 2) como la reacción afectiva vicaria ante otra persona. Hoffman (2000) manifiesta que la empatía requiere la participación de unos procesos psicológicos que hagan que los sentimientos de una persona sean más congruentes con la situación de otra que con la suya propia. Habla de aflicción empática como un motivo prosocial, tiene relación con la ayuda y precede a la misma. Para Hoffman, la empatía es una respuesta afectiva vicaria que es más adecuada a la situación de algún otro que a la propia situación y que incluye sentimientos de dolor somático y culpabilidad basada en la empatía. El "dolor simpático" es un sentimiento negativo acerca de uno mismo como respuesta a causar daño a alguien, es la compasión por alguien que sufre pena?

Naval (1995) resume la postura de Hoffman (1982) destacando que la socialización, especialmente aquella proporcionada por los padres, juega un papel

9. A veces el adulto es ambivalente cuando se empatiza con él, sobre todo cuando se le ayuda. Esto puede ocurrir tras una larga enfermedad o un período de duelo. Un ejemplo del libro de Hoffman así lo ilustra: "Cuando ocurrió la muerte de mi padre me conmocionó y me alteró mucho. Deje de ir una 
importante en desarrollar respuestas de participación afectiva y emotiva y superar las necesidades y deseos egoístas. Identifica muchos tipos de experiencias de socialización que contribuyen a mejorar la sensibilidad y motivación moral: permitiendo al niño experimentar un amplio rango de emociones, llamándole la atención hacia los sentimientos de los otros, usando técnicas disciplinares que subrayen el sufrimiento de los otros o que faciliten adoptar la perspectiva de la víctima, tomando parte en oportunidades de asumir papeles, especialmente en contextos no competitivos, proveyéndole de afecto para ayudarle a mantenerse abierto a las necesidades de los otros y no completamente absorbido en sus propias necesidades, y exponiéndole a modelos que son altruistas y que expresan sentimientos simpáticos.

Numerosos estudios indican que cuando alguien presencia la aflicción ajena lo típico es que reaccione de forma empática o con una acción claramente auxiliadora. Además se ha comprobado que los observadores se sienten mejor tras haber ayudado a alguien.

La mayoría de las personas atribuimos espontáneamente la causa de los sucesos (Weiner, 1985) y, sin duda, se hace también cuando vemos afligirse a alguien, a esto se le denomina atribución causal.

Se ha evidenciado con estudios e investigaciones que el ser incapaz de empatía no predestina a nadie a manipular o matar pero, sin duda, puede conducir a la agresividad y a la capacidad de manipular a los demás. La aptitud de una persona para empatizar del todo con otro está ligada a su comprensión de lo que subyace a los sentimientos ajenos, esta comprensión se desarrolla desde la primera infancia, en la adolescencia e incluso en la edad adulta.

Colby y Damon (1992) realizaron una investigación publicada en la obra Some do care, donde destacan algunos criterios que deben cumplir las personas para poder ser cuidadosas y compasivas: 1) un compromiso permanente con principios morales que incluyen un respeto generalizado por la humanidad o una evidencia de virtud moral; 2) una disposición para actuar de acuerdo con los principios morales, lo que implicaba una consistencia entre las acciones y las intenciones, los medios y los fines; 3) la voluntad para arriesgar los intereses personales en beneficio de los valores morales. No se trataba de que fueran mártires sino de que cuando su bienestar personal chocaba con su moralidad, entonces sus principios eran determinantes, poniendo en riesgo su economía, su vida familiar o su seguridad personal por no traicionarlos; 4) una tendencia a inspirar a otras personas para la acción moral (una capacidad para contagiar su visión del mundo y su acción de ayuda); 5) humildad en torno a su importancia y una despreocupación por su ego.

\footnotetext{
semana a la universidad para centrarme, y después sólo quería que mi vida retrocediera antes de la muerte. Pero cuando la gente me llamaba sus palabras eran siempre de compasión y lástima. Yo no quería que me hablasen de tristeza ni ponerme triste. Lo que quería era seguir viviendo, pues había aceptado la muerte y estaba dispuesta a seguir adelante. Quería por tanto hablar de otras cosas y reír, pero no podía porque aún había personas sufriendo a mi alrededor y reír no me parecía bien" (estudiante universitaria). Este ejemplo está muy cercano a una experiencia reciente vivida por la autora.
} 
También, descubrieron que las personas que cumplían con estos requisitos compartían tres características comunes en su personalidad: 1) certeza, 2) espíritu positivo, 3) unidad del yo con unas metas morales.

Hansen (2002), a este respecto, introduce la idea de "sensibilidad" que evoca palabras como considerado, reflexivo, paciente. La sensibilidad contrasta con el sentimiento y la emoción en cuestiones del corazón, del alma, de las pasiones. Sin embargo, el crecimiento humano requiere tanto de la reflexión como de la emoción, tanto la mente como el corazón. El llegar a ser persona consiste en aprender a armonizar ambos en la conducta.

La sensibilidad moral representa la disposición de una persona ante la vida, las personas y los acontecimientos a los que se enfrenta, describe cómo combina la humanidad con la reflexión en su manera de considerar y tratar a los demás. Una sensibilidad moral presenta una orientación crítica.

\section{5. ÉtICA DE LA ALTERIDAD Y DE LA COMPASIÓN}

El punto de vista de la filosofía judía aporta un elemento más a la autonomía, porque reclama una responsabilidad previa por parte del sujeto ante el otro, del otro. Nos parece esencial la propuesta de Mèlich $(2000,87)$ de una nueva concepción de la subjetividad, la identidad y la acción educativa, partiendo de una crítica al principio de autonomía, a las éticas formales y procedimentales, y a la razón dialógica y comunicativa, que desde nuestro grupo de investigación hemos defendido en numerosas publicaciones y trabajos. Pero creo que no ha realizado un análisis profundo de nuestro planteamiento, porque los sentimientos morales, como la compasión, no dejan de contemplarse aunque no explícitamente.

De todas formas, sus ideas pueden y deben ser tenidas en cuenta sobre todo porque proponen una mirada distinta a la educación moral que, como ya hemos mencionado, resulta de indudable interés. Cierto es que Mèlich (2000) se basa en Levinas en muchas de sus consideraciones pedagógicas, y nos invita a reflexionar cuando expone en términos de Levinas que "a este cuestionamiento de mi espontaneidad por la presencia del otro se llama ética", porque la autonomía se fundamenta en la heteronomía y sólo a través de la heteronomía puede el sujeto convertirse en autónomo. La presencia del otro, como heteronomía privilegiada, no niega mi libertad, ni la dificulta. Todo lo contrario, la inviste (Levinas, 1977, 110).

Y añade que la subjetividad humana es constitutivamente ética y la relación educativa sólo puede ser genuinamente educativa a partir de la ética. La ética es el principio constitutivo de la educación y de la subjetividad humana. Desde esta perspectiva, la educación aparece como una relación de alteridad, en la que el yo ha depuesto su soberanía, su orgullo de yo. El yo en la relación educativa se configura como respuesta al otro.

Mèlich nos acerca, además, a la traducción pedagógica del planteamiento de Levinas, refiriéndose al libro de Max Van Manen El tacto en la enseñanza. 
El asunto que es sensible a la vulnerabilidad o la necesidad del niño, experimenta una extraña sensación: la verdadera autoridad en este encuentro está en el niño y no en el adulto. Podríamos decir que la presencia del niño se convierte para el adulto en la experiencia de enfrentarse con una exigencia de su receptividad pedagógica. Por tanto, la debilidad del niño se convierte en una curiosa fuerza sobre el adulto. Por consiguiente, en varios sentidos, la autoridad pedagógica le concede al niño, y se produce en un encuentro que el adulto experimenta a través de la responsabilidad que tiene ante el niño (Van Manen, 1988, 84).

Y nos alerta de que esta forma de entender la relación educativa rompe radicalmente con las filosofías de la educación que presentan el principio de autonomía como pilar constitutivo de la pedagogía.

La perspectiva en la que hemos venido trabajando durante las dos últimas décadas está soportada por tres criterios básicos: la autonomía, la razón dialógica y la diferencia (Buxarrais, 1997), entendiendo que los conflictos de valores y su resolución a través del diálogo pueden ayudar al desarrollo moral de la personas y les ayudan a fundamentar formas de convivencia personal y colectiva más justas.

Una apuesta por un planteamiento filosófico y pedagógico que no es sólo la autonomía o la libertad, como tampoco, el diálogo, sino la heteronomía o la responsabilidad, la compasión y la memoria, las que hacen posible una teoría de la educación que tenga presente los acontecimientos del siglo XXI. Responder al otro se convierte en una respuesta previa a todo consenso y a todo consentimiento. Así, Payà $(1997,195)$ afirma que la consecución de una moral autónoma sin más, sin la consideración de la otra persona "Con rostro" invalidaría todo proceso comunicativo y dialógico y no constituiría tampoco optimización y desarrollo humano. Sin embargo, el respeto a la dignidad de la otra persona permite descubrir y alcanzar en su plenitud el ideal de autonomía.

Llegados a este punto, nuestro esfuerzo descansará en apuntar algunas propuestas pedagógicas sostenidas en la compasión, la alteridad, el cuidado y la responsabilidad, entre otros. Sólo si todo lo que precede a estas líneas tiene una traducción en la praxis educativa nos daremos por satisfechas.

Dos han sido los destinos de esta ética para la compasión en educación: el espacio de las relaciones interpersonales (profesor-alumno) y el enfoque narrativo en el desarrollo moral.

\subsection{El espacio de las relaciones interpersonales en educación}

Los vínculos personales que se establecen entre profesores y alumnos constituyen un lugar donde puede y debe practicarse la compasión. La interacción entre profesores y alumnos se concreta en momentos de encuentros, relaciones cara a cara entre dos sujetos que a través de su rostro, el gesto y la palabra crean un vínculo mutuo y se implican en una situación no programada de participación conjunta en una tarea formativa (Gijón, 2003). Resultará importante generar una actitud educativa 
dispuesta a evitar los meros contactos en favor de encuentros auténticos y dispuesta también a crear situaciones y prácticas formativas que faciliten la multiplicación de encuentros personales donde la sensibilidad del docente y la práctica de la compasión generarán una auténtica educación moral, porque como afirma Puig (2005) para que se produzca una relación educativa auténtica no basta con una sucesión de encuentros, es necesario que el encuentro contenga una clara iniciativa del educador orientada a acoger, reconocer y aceptar al educando (Duch, 1997).

Otra de las cuestiones que nos surgen cuando nos referimos a las relaciones interpersonales en educación es la idea de la "sensibilidad" aplicada a la docencia. Una sensibilidad moral del profesor subraya la importancia de la manera en que un profesor piensa y actúa, y no sólo de lo que dice o hace. El ejemplo que nos propone Hansen $(2002,51)$ lo ilustra: dos profesores pueden ofrecer las mismas instrucciones para una actividad en pequeños grupos o idénticas explicaciones para interpretar poesía. Pero uno de los profesores quizás es brusco e impaciente $y$ transmite el mensaje de que no confía en sus alumnos o de que no le gustan. $O$ tal vez se comporta de un modo despreocupado e informal, lo que indica que no le importa el resultado del ejercicio. El otro profesor, sin embargo, quizás proporcione los mismos comentarios pero con un espíritu entusiasta y de apoyo, con lo que expresará su implicación en la enseñanza y su confianza en la capacidad de aprender de los alumnos. No es fácil imaginar qué clase preferirán los alumnos. Su elección reflejará el hecho de que los profesores no son tan distintos por sus conocimientos técnicos o su experiencia como por su sensibilidad. Así pues, podemos hablar de la presencia moral del profesor o maestro en la vida de los alumnos.

Ortega (2004) ya nos advertía del debate en torno a que la relación entre maestro y alumno es una relación ética que debería traducirse en una actitud de acogida y de compromiso hacia el alumno, haciéndose cargo de él. Por lo tanto, de las estrategias en educación moral que hemos empleado hasta el momento, deberíamos potenciar con más entusiasmo aquellas en las que se desarrollase la dimensión afectiva de la persona, estrategias socioafectivas. Aquellas que incidan en aspectos como: el interés por el otro, la empatía, la preocupación por los asuntos de la comunidad, la solidaridad, la tolerancia, el civismo, etc.

Es necesaria "la incorporación de un nuevo lenguaje y unos nuevos contenidos en educación; si el adiestramiento técnico-profesional, indispensable como objetivo educativo en los procesos de enseñanza, deba ir acompañado de otros aprendizajes morales, y situar entonces el discurso pedagógico no ya sólo en los medios, sino en el qué y para qué" (Fullat, 1997). Es necesario, en una palabra, recuperar el discurso antropológico y ético que da sentido a la acción educativa (Escámez, 2003).

Allí donde acontece la educación se produce un encuentro no del que sabe con el que no sabe, del profesor con el alumno, en un ejercicio de transmisión de saberes, sino el encuentro del que se sabe responsable del otro, obligado a darle una respuesta en su situación de radical alteridad. El profesor se convierte en un mediador moral que facilita la construcción personal del alumno. 
La relación ética de acogida es lo que define a la relación profesor-alumno como relación educativa.

"Entre educador y educando no hay poder. El poder convierte la asimetría en posesión y opresión, al educador en amo y al educando en esclavo" (Mèlich, 1988, 149). En palabras de Levinas (1993) "Acoger al otro en la enseñanza... es acoger lo que me trasciende y lo que me supera; lo que supera la capacidad de mi yo y me obliga a salir de él, de un mundo centrado en mí mismo, para recibirlo" (Bárcena y Mèlich, 2000, 160). Así pues, la relación educativa entre educador y educando no es una relación convencional, profesional, que se puede encerrar en un lenguaje en el que todos los problemas, transformados en cuestiones técnicas, puedan ser resueltos, controlados y dominados. Más allá de una actividad técnica o profesional, la educación, en sí misma, es un acontecimiento ético, una experiencia ética, no una relación entre profesor y alumno "rebosante de posibilidades morales" (Buzzelli y Jonson, 2002), ni un experimento en el que la referencia a la ética le venga "desde fuera".

Después de la acogida, de la aceptación de la persona del otro en su realidad concreta, en su tradición y cultura, se da un reconocimiento del otro como alguien, valorado en su dignidad irrenunciable de persona, y debería añadirse el sentimiento de la compasión, una compasión entendida como hacerse cargo del otro, asumir la responsabilidad de ayudar al nacimiento o alumbramiento de una "nueva realidad" a través de la cual el mundo se renueva sin cesar (Arendt, 1996). La acogida, la compasión, el hacerse cargo del otro, cuidarle, se convierten en características propias e indispensables de la educación.

En el momento de nacer, el hombre es un ser desvalido y desorientado; le faltan puntos de referencia fiables y, sobre todo, lenguajes adecuados para poder instalarse en el mundo, es decir, para humanizarse en el mismo acto de humanizar su entorno... Para llevar a cabo esa tarea con ciertas garantías de éxito, necesitará de un conjunto de transmisiones que le faciliten la inserción en el trayecto vital que le corresponde, en cuyo recorrido, deberá ser acogido en el seno de una comunidad y reconocido por ella (Duch, 2002, 11-12).

Coincidimos con Ortega (2003) cuando propone una pedagogía de la alteridad, incorporando los elementos positivos de otros modelos o enfoques de la educación, porque de esa forma se podrá responder mejor a las exigencias éticas, originarias de la educación. Desde esta pedagogía, el proceso educativo se inicia con la mutua aceptación y reconocimiento de maestro y alumno, en la voluntad de responder del otro por parte del profesor, en la acogida gratuita y desinteresada que presta al alumno de modo que éste perciba que es alguien para el profesor y que es reconocido en su singularidad personal. Sin reconocimiento del otro y compromiso con él no hay educación ${ }^{10}$.

10. "En la mejor de sus formas, escribe $\operatorname{STEINER}(1998,155)$, la relación maestro-alumno es una alegoría del amor desinteresadom. 
En la pedagogía de la alteridad la acogida del otro significa sentirse reconocido, valorado, aceptado y querido por lo que uno es y en todo lo que es. Significa confianza, acompañamiento, guía y dirección, pero también aceptar ser enseñado por "el otro" (educando) que irrumpe en nuestra vida (educador).

La educación como experiencia de acogida, no sólo en el profesor sino también en el alumno (reconocimiento del otro y hacerse cargo de él), facilita la creación de un clima moral en el centro y en las aulas como "condición ambiental" para el aprendizaje de los valores sociomorales.

En esta misma línea, ya Levinas manifiestaba una clara voluntad en sustituir la autorreflexión, la autoconciencia, fundamento de una ética individualista, por la relación con el otro, como una propuesta de una moral alternativa. No creemos que una deba ser alternativa de la otra, sino que ambas pueden conciliarse. Por supuesto, debemos desarrollar junto con la dimensión racional, una dimensión afectiva. Esto se traduce en el desarrollo de la empatía, del diálogo, de la capacidad de escucha y atención al otro (estar pendiente del otro), de la compasión, como condición primera de una relación ética, pero no debemos olvidar el desarrollo de la comprensión crítica de la realidad desde parámetros de justicia y equidad, de asumir al educando en toda su realidad, porque al ser humano no se le puede entender si no es en su entorno, en la red de relaciones que establece con los demás.

Entonces, la respuesta moral a la presentación del "otro" es la compasión, entendida como cuestión de "entrañas", de sufrimiento compartido, de calidad humana, en definitiva, como cuestión moral. La moral encuentra en la "com-pasión" su momento más completo.

\subsection{El enfoque narrativo en el desarrollo moral}

En las últimas décadas el enfoque narrativo ha ido tomando consistencia y se ha convertido en una línea de comprensión de la experiencia y el desarrollo moral clave para los entornos educativos. Se ha comprobado que el relato de los individuos es constituyente básico de su identidad moral. Además, la experiencia moral tiene un carácter específico: ocurre en un espacio y tiempo determinado, en contextos relacionales de la vida cotidiana, con individuos arraigados en una historia personal y social. Por eso cuando se quiere contar "lo que realmente sucedió" se recurre a la narración. A través de los relatos la gente cuenta sobre su vida moral, hablan sobre lo que hacen, lo que sienten, lo que les sucedió y las consecuencias de sus acciones, siempre situados en la relación con el otro, no desde un yo solitario e imparcial. Ya Ricoeur (1996, 185), citado por Bárcena y Mèlich (2000) decía que "interpretar el texto de la acción, es, para el agente, interpretarse a sí mismo". Construir la vida es, como decía Unamuno, "hacer una novela", o como señalaba Aranguren, "cada vida es un texto que cada cual se escribe a sí mismo, estamos hechos de la estrofa de nuestros relatos". 
Una de las tesis centrales del marco conceptual de la narrativa (Bruner, 1987) es entender la vida como un "texto" que nos relatamos a nosotros mismos o a otros, sometido a exégesis, interpretación y reformulación. En el relato el sujeto cobra una identidad narrativa: “La historia narrada dice el quién de la acción. Es contando nuestras propias historias como nos damos a nosotros mismos una identidad. Nos reconocemos en las historias que contamos sobre nosotros mismos" (Ricoeur, 1987).

El relato narrativo ${ }^{11}$ es, entonces, un modelo de comprensión y expresión de la vida, donde está presente la voz del autor/agente. Nos permite expresar la singularidad de cada acción, frente a las deficiencias de un modo atomista y formalista de descomponer las acciones en un conjunto de variables discretas (PérezDelgado, 1999, 88).

En el enfoque narrativo del desarrollo moral confluyen varias líneas o disciplinas de orientación "hermenéutica" y de corte postmoderno. La llamada "psicología narrativa" adopta la metáfora de "vida como narrativa" entendida con elementos similares a los relatos de ficción o literarios: trama, acción, secuencialidad, etc.

En la línea de la ética de la compasión, nos topamos otra vez con Gilligan, con su hermenéutica psicológico-narrativa, a partir de la que se realiza una comprensión de la complejidad psicológica de las narraciones que los individuos hacen de los conflictos y de los dilemas de su vida. En lugar de situarse en el "debe" se habla desde el "es" por lo que la orientación de la justicia versus el cuidado es psicológica, no filosófica. Trata de captar dos visiones diferentes de las relaciones humanas deseables: visión ideal de la igualdad, reciprocidad e imparcialidad de las relaciones entre las personas; frente (voz del cuidado/solicitud) a una visión ideal de las relaciones de amar y ser amado, escuchar y ser escuchado, derivada de unas experiencias en el niño de amor y comprensión entre padres e hijos. Hay, pues, dos modos de hablar: el lenguaje aceptado y el lenguaje silenciado.

En último extremo, una de las claves del enfoque narrativo es un concepto ampliado de la identidad y agente (self) moral, que comprenda las dimensiones relacional, afectiva y comunicativa.

Por su parte, Noddings (1984) partiendo de que ser es "ser-con", delimita el campo de la ética de la compasión como un "sentir-con", como una ética primaria, en la medida que nuestra supervivencia como seres humanos depende de un nuevo renacer los sentimientos humanos (amistad, comunidad humana, parentesco y amor mutuo). La relación madre-hijo sería el caso paradigmático para entender lo que entraña la ética del cuidado o de la compasión, por el otro. "Sentir-con" es una reacción natural, espontánea, de empatía natural y de compromiso moral por los otros concretos. En sentido similar, Gilligan había definido la moralidad como una responsabilidad solidaria por el otro.

11. Muchos profesores cuentan anécdotas e historias sobre sus experiencias cotidianas a los niños. Esta actividad resulta útil porque permite al alumno saber cómo analizar una experiencia o acontecimiento, cómo interpretar lo importante y qué acción tomar (VAN MANEN, 1998, 209). 
No se trata de recluir la ética del cuidado y de la compasión al campo de la moral feminista, porque se prestaría un flaco servicio a dicha moral, sino que se trata de defender que tanto la ética de la justicia como la del cuidado deben estar presentes social y educativamente, subrayando quizás en estos momentos la ética del cuidado por haber estado silenciada.

El enfoque narrativo tiene relevantes implicaciones en la educación moral. En lugar de utilizar dilemas morales hipotéticos como estrategias didácticas, se utilizan otras estrategias que comprometan a los participantes en problemas reales de conflicto moral y elección, vividos por ellos mismos en el aula o, sobre todo, fuera de ella, en la realidad cotidiana. Los niños no sólo deben ser considerados como "pequeños filósofos morales", sino seres reales en donde las emociones, sentimientos, deseos, afectan a su razonamiento moral y deben, por tanto, formar parte de la discusión. Por eso, también los aspectos afectivos y emotivos deben tener un lugar relevante.

En primer lugar los profesores deben proporcionar oportunidades a sus alumnos para que éstos cuenten sus propias historias o relatos de vida, en sus propios términos, tomando autoría sobre sus perspectivas y experiencias morales. En un segundo nivel, se debe inducir a reflexionar sobre sus experiencias desde una perspectiva moral, incrementando el sentido de responsabilidad sobre sus propias acciones. En este sentido, narrar historias de vida es hacer una autointerpretación del agente, la identidad es narrativa. Noddings (1992) ha hecho una propuesta curricular basada en la ética del cuidado.

Benhabid (1990) propone un "universalismo interactivo" o dialógico que reconozca que el otro generalizado es también un otro concreto: «una teoría moral que nos permita reconocer la dignidad del otro generalizado mediante el reconocimiento de la identidad moral de otro concreto" (Benhabit, 1990, 144).

\section{CONCLUSIÓN: EL RETORNO DE LA COMPASIÓN}

La ética de la compasión es un modo de estar en el mundo como una exploración y justificación más o menos sistemática de las decisiones morales que tomamos en ese mundo, donde el valor del placer sin límites se nos ofrece día a día. Nos advierte del peligro de fomentar la autonomía de tal forma que se consigan individuos autónomos como aquellos que están liberados de vínculos y formas de dependencia que, aunque no deseables en muchos casos, están presentes. La propuesta de límites ordenadores (heteronomía) a los jóvenes facilitará su posterior autonomía.

De una cosa estamos seguros, y es que la compasión puede enseñarse y aprenderse. Educando a nuestros jóvenes como personas moralmente comprometidas estaremos en el camino de conseguirlo. Promocionar la sensibilidad moral hacia los deseos del otro, sus problemas, sus intereses, etc., supone en cierto modo "maternalizar" la sociedad, pero significará un cambio, no sólo en las formas sino 
en la mirada, que nos permitirá avanzar en aras a "hacer posible un nuevo estado de cosas, una nueva sociedad fundamentada en la justicia y la equidad; más aún en la solidaridad y la compasión" (Ortega y Mínguez, 2001, 120).

En este sentido, los que nos dedicamos a la educación debemos interpelarnos y realizar un ejercicio comprometido imaginando futuros posibles y dibujando un horizonte común. Apostar por un tipo de educación que asuma el sufrimiento ajeno como algo injusto, que haga de la responsabilidad frente al otro, y del compromiso del actual, una cuestión irrenunciable. Abogamos por una educación entendida como el acogimiento de los vulnerables, de los que sufren la exclusión social (Martínez y Tiana, 2004). No es posible la salida de la marginación y la pobreza sin un cambio profundo en las mentalidades de las personas que no sufren dicha marginación y pobreza.

Proponemos una praxis educativa de la ética de la compasión en la educación (Ortega y Mínguez, 2001, 125) que nos lleve a un trabajo más intenso en el desarrollo de la empatía, compartir afecto y sentir con el otro, realizando un entrenamiento afectivo; el desarrollo de las habilidades para el diálogo, de escucha activa y de participación social; el desarrollo de la capacidad crítica para darnos cuenta de qué está pasando en el mundo que nos rodea, cuáles son las condiciones de vida de las personas, el respeto a su dignidad y la experiencia del sufrimiento.

La educación, en consecuencia, no debe olvidarse de la compasión, porque a pesar de que el ser compasivo exija, evidentemente, unas cualidades personales, un temperamento, se genera también mediante la adquisición de hábitos y actitudes en los distintos contextos educativos.

Nos gustaría terminar nuestro artículo con una cita de Miquel Martínez, quien, pese a que no ha tratado el tema de la compasión de forma explícita, sí lo tiene en consideración cuando habla de los sentimientos morales como uno de los puntales de la construcción de ciudadanos y ciudadanas justas, equitativas y solidarias.

Nuestro mundo requiere ciudadanía con capacidad para comprender críticamente, razonar éticamente, sentir moralmente, elaborar criterios personales de forma autónoma y actuar de acuerdo con ellos en el marco de un modelo de aprendizaje ético que procure la transformación de nuestro entorno para el logro de mayores niveles de felicidad, libertad y equidad para todos (Martínez, 2004, 20). 


\section{BiBLIOGRAFÍA}

ARENDT, H. (1996) Entre el pasado y el futuro. Barcelona, Península.

- (1999) Los orígenes del totalitarismo. Madrid, Taurus.

ARTETA, A. (1997) La compasión. Apología de una virtud bajo sospecha. Barcelona, Paidós.

BÁrCENA, F. (2002) Educación y experiencia en el aprendizaje de lo nuevo, Revista Española de Pedagogia, 223, 501-520.

Bárcena, F. y Mèurh, J. C. (2000) La educación como acontecimiento ético. Barcelona, Paidós.

Bauman, Z. (2005) Vidas desperdiciadas. Barcelona, Paidós.

Bello, G. (1997) La construcción ética del otro. Oviedo, Nobel.

BENHABID, S. (1990) El otro generalizado y el otro concreto: la controversia Kohlberg-Gilligan y la teoría feminista, en BENHABID, S. y CORNell, D. Teoría feminista y teoría crítica. Valencia, Editorial Alfons el Magnànim, 119-149.

BERKOWITZ, M. W. (1995) Educar a la persona moral en su totalidad, Revista Iberoamericana de Educación, n. ${ }^{\circ} 8,73-101$.

Bernal, A. (2002) El voluntariado. Educación para la participación social. Barcelona, Ariel social.

Blum, L. (1994) Moral perception and particularity. Cambridge, Cambridge University Press.

Boff, L. (1999) Saber cuidar: ética de la bumano-compaixao pela terra. Petrópolis, Vozes.

Brugère, F. (2006) La sollicitude. La nouvelle donnée afective des perspectives feministes, Esprit, Monográfico: Les nouvelles figures de soin. Paris, 123.

BRUNER, J. (1988) Realidad mental y mundos posibles. Barcelona, Gedisa.

- (1997) La educación, puerta de la cultura. Madrid, Aprendizaje-Visor.

BUXARRAIS, M. R. (1997) La formación del profesorado en educación en valores. Propuestas y materiales. Bilbao, Desclée de Brouwer.

- (2000) Tendencias y modelos de educación moral, Diálogo Filosófico, n. ${ }^{\circ} 47,196-220$.

CAMPs, V. (1999) Paradojas del individualismo. Barcelona, Crítica.

Castel, R. (1991) De l'indigence à l'exclusion. La désafilitation, en Donzelot, J. (coord.). Face a l'exclusion de modèle français. Paris, Esprit, 137-168.

COLBY, A. y DAMON, W. (1992) Some do care. Contemporary lives of moral commitment. New York, Free Press.

Dalai lama (2000) El arte de vivir en el nuevo milenio. Una guía ética para el futuro. Barcelona, Grijalbo.

Duch, Ll. (1997) La educación y la crisis de la modernidad. Barcelona, Paidós.

- (2002) Antropología de la vida cotidiana. Madrid, Trotta.

Elshtain, J. B. (1980) Public Man, Private Woman. Princeton, Princeton University Press.

Escámez, J. (2003) Los valores y la educación en España, en AA.VV. Teoría de la Educación, ayer y boy. Murcia, SITE, 205-233.

EscámeZ, J. y GIL, R. (2003) La educación en la responsabilidad. Barcelona, Paidós.

Fullat, O. (1997) Antropología filosófica de la educación. Barcelona, Ariel.

GARRIDO, V. (2005) Los hijos tiranos. El sindrome del emperador. Barcelona, Ariel.

GIJón, M. (2004) Encuentros cara a cara. Valores y relaciones interpersonales en la escuela. Barcelona, Graó.

GILIGGAN, C. (1982) In a different voice: psychological theory and women's development. Cambridge, Harvard Univ. Press.

- (1985) La moral y la teoría. Psicología del desarrollo moral femenino. México, FCE.

- (2003) El nacimiento del placer. Una nueva geografía del amor. Barcelona, Paidós. 
Goleman, D. (1996) Inteligencia emocional. Barcelona, Kairós.

Gómez SÁnchez, C. (1997) Defensa de la compasión. En contra de sus entusiastas, Revista Sistema, Revista de Ciencias Sociales, n. ${ }^{\circ} 139,45-66$.

Grün, A. (2001) Portarse bien con uno mismo. Salamanca, Sígueme.

Habermas, J. (1996) Textos y contextos. Barcelona, Ariel.

HANSEN, T. (2002) Explorando el corazón moral de la enseñanza. Barcelona, Idea Books.

HOFFMAN, M. L. (1982) Development of prosocial motivation: Empathy and guilt, en EISENBERGBerge, N. (ed.). Development of Prosocial Behavior. New York, Academic Press, 281-313.

- (2002) Desarrollo moral y empatía. Barcelona, Idea Books.

HolsteIN, C. B. (1969) Parental consensus and interaction in relation to the child's moral judgment. Berkeley. Existe microfilmación de esta tesis en la colección de microfilms de la Universidad de California.

Hoyos, G. (1995) Ética comunicativa y educación para la democracia, Revista Iberoamericana de Educación. Madrid, OEI, 65-92.

Hoyos, G. y MARTínez, M. (coords.) (2004) ¿Qué significa educar en valores hoy? Madrid, Octaedro.

Hume, D. (1977) Tratado de la naturaleza bumana. Madrid, Editora Nacional.

ICKES, W. (1997) Empathic accuracy. New York, Guilford.

Katz, M. S.; Noddings, N. y StRIKe, K. A. (2002) Justicia y cuidado. En busca de una base ética común en educación. Barcelona, Idea Books.

Kung, H. (1992) Proyecto de una ética mundial. Madrid, Trotta.

Levinas, E. (1977) Totalidad e infinito. Salamanca, Sígueme.

- (2000) Ética e infinito. Madrid, La Balsa de la Medusa.

LEwIs, C. S. (1994) Los cuatro amores. Madrid, Rialp.

Martínez, M. y Bujons, C. (coords.) (2001) Un lugar llamado escuela en la sociedad de la información y la diversidad. Barcelona, Ariel.

Martínez, M.; Puig, J. M. y Trilla, J. (2003) Escuela, profesorado y educación moral, Revista de Teoria de la Educación. Salamanca, Ediciones Universidad, vol. 15, 57-94.

Martínez, M. y Tiana, A. (2004) Educación, valores y cobesión social, en http://www. ibe.unesco.org.

Mate, R. (2003) En torno a la justicia anamnética, en Mardonés, J. M. y Mate, R. (eds.). La ética de las víctimas. Barcelona, Anthropos, 11-26.

MèLıCH, J. C. (2003) La sabiduría de lo incierto. Sobre ética y educación desde un punto de vista literario, Educar, n. ${ }^{\circ} 31,33-45$.

MÈLICH, J. C. y otros (2000) La veu de l'altre. Reflexions i experiències per educar en valors ètics. Barcelona, ICE-UAB.

MORIN, E. (1982) Ciencia con conciencia. Barcelona, Anthropos.

NAVAL, C. (1995) Educar ciudadanos. La polémica liberal-comunitarista en educación. Pamplona, Eunsa.

- (2001) Confiar: cuna de la sociabilidad bumana. San José de Costa Rica, Promesa.

NodDings, N. (2002) Educating moral people: a caring alternative to character education. New York, Teachers College Press.

Ortega, P. (1997) De la ética de la compasión a la pedagogía del encuentro, en Ortega, P. (coord.). Educación Moral. Murcia, Caja Murcia, 91-108.

- (2004) La educación moral como pedagogía de la alteridad, Revista Española de Pedagogia, n. ${ }^{\circ} 227,5-30$. 
Ortega, P. y Mínguez, R. (1999) The Role of Compasión in Moral Education, Journal of Moral Education, 28, 5-17.

- (2001) La educación moral del ciudadano de boy. Barcelona, Paidós.

PAYÀ, M. (1997) Educación en valores para una sociedad abierta y plural. Bilbao, Desclée de Brouwer.

Pérez Delgado, E. y Mestre, M. V. (coords.) (1999) Psicología moral y crecimiento personal. Barcelona, Ariel Psicología.

Puig, J. M. (1996) La construcción de la personalidad moral. Barcelona, Paidós.

- (2003) Prácticas morales. Una aproximación a la educación moral. Barcelona, Paidós.

Ricoeur, P. (1987) El tiempo contado, Revista de Occidente, n. ${ }^{\circ}$ 76, 41-64.

Rousseau, J. J. (1987) Emilio. Madrid, Edaf.

Ruddick, S. (1989) Maternal Thinking. Towards a Politics of Peace. Boston, Beacon Press.

SANZ DE SANTAMaría, A. (2005) La compasión en la educación, en Toro, J. B. (ed.). La educación desde las éticas del cuidado y la compasión. Colombia, Universidad P. Javeriana.

Striner, G. (1998) En el castillo de Barba Azul. Barcelona, Gedisa.

STOuT, M. (2005) The sociopath next door. New Cork, Broadway Books.

STRawson, P. (1995) Libertad y resentimiento. Barcelona, Paidós.

TAYLOR, S. E. (2002) Lazos vitales. De cómo el cuidado y el afecto son esenciales para nuestras vidas. Barcelona, Taurus.

Tugendath, E. (1999) Diálogo en Leticia. Barcelona, Gedisa.

VAN MANEN, M. (1998) El tacto en la enseñanza. El significado de la sensibilidad pedagógica. Barcelona, Paidós Educador.

WeINER, B. (1985) “Spontaneous" causal thinking, Psychological Bulletin, 97, 74-84.

YEY, A. (2005) Educació dels sentiments morals $i$ aprenentatge ètic: La perspectiva del professorat. Tesis doctoral inédita.

YeY, A. y MARTíneZ, M. (2003) Educar en valors és educar en sentiments morals, Educar, n. ${ }^{\circ}$ 31, 11-32.

ZACCAİ-REYNERS, N. (2006) Respect, réciprocité et relations assimétriques. Quelques figures de la relation de soin, Esprit, Monográfico: Les nouvelles figures de soin. Paris, enero, 95. 